\title{
Influence of low-level laser irradiation on osteocalcin protein and gene expression in bone tissue ${ }^{1}$
}

Fernando Russo Costa do Bomfim', Valeria Regina Gonzalez Sella", Ronaldo Luís Thomasini"', Helio Plapleriv

'BSc, MSc, Fellow PhD degree, Postgraduate Program in Interdisciplinary Surgical Science, Universidade Federal de São Paulo (UNIFESP), Brazil. Conception and design of the study, acquisition of data, histopathological examinations, manuscript writing.

"PhD, Operative Technique and Experimental Surgery Division, Department of Surgery, UNIFESP, Sao Paulo-SP, Brazil. Technical procedures, manuscript preparation.

I'BSc, PhD, Full Professor, Medicine Faculty, Universidade Federal dos Vales do Jequitinhonha e Mucuri (UFVJM), Diamantina-MG, Brazil. Acquisition, analysis and interpretation of data; critical revision.

IVPhD, Full Professor, Operative Technique and Experimental Surgery Division, Department of Surgery, UNIFESP, Sao Paulo-SP, Brazil. Manuscript writing, critical revision, final approval.

\begin{abstract}
Purpose: To evaluate osteocalcin gene and protein expression in vitro and in an in vivo model of ostectomy.

Methods: Twenty Wistar rats were assigned into two groups $A(n=10$, laser) and $B(n=10$, control). Ostectomy was performed in the femur diaphysis; the twenty fragments removed, composed in vitro groups named as in vivo ( $\mathrm{A}$ and $\mathrm{B}$ ) and cultivated in $\mathrm{CO}_{2}$ atmosphere for thirteen days. Low-level laser irradiation was performed in groups $A$ (in vivo and in vitro) by an GaAlAs device $\left(\lambda=808 \mathrm{~nm}\right.$, dose of $2 \mathrm{~J} / \mathrm{cm}^{2}$, power of $200 \mathrm{~mW}$, power density of $0.2 \mathrm{~W} / \mathrm{cm}^{2}$, total energy of $1.25 \mathrm{~J}$, spot diameter of $0.02 \mathrm{~mm}$ ) for 5 seconds, at one point, daily. It was performed immunocytochemistry assays in vivo and in vitro groups. In vitro groups were also submitted to RNA extraction, cDNA synthesis and gene expression by quantitative PCR. Statistical analysis was realized with $p<0.05$.

Results: Immunocytochemistry scores showed no significant differences between control and laser groups either in vivo and in vitro. Gene expression also showed no statistical differences. Conclusion: Low-level laser irradiation did not alter osteocalcin protein and gene expression in vivo and in vitro in the studied period but it may have been expressed them in an earlier period.
\end{abstract}

Key words: Low-Level Light Therapy. Osteocalcin. Bone. Rats. 


\section{Introduction}

According to the World Health Organization, there are more than 150 diseases and syndromes related to skeletal and joint problems. Approximately six million long-bone fractures are reported annually in the USA. Although progress has been made in treatment methods over the past decades, approximately $5-10 \%$ of fractures still result in delayed union or non-union. Moreover, 600.000 individuals experience prolonged pain and discomfort associated with fracture non-union. This data reports that bone fractures are related to functional disease, disability and burden in world $^{1-3}$.

Several treatments were described to bone fractures as internal fixation of fractures that preserve anatomy and early function, although reconstruction and absolute stability of fixation were essential preconditions for success. Besides, shock wave treatment can be used to promote bone healing because produce bone micro fractures, which can stimulate osteoblast synthesis, neovascularization and bone callus. However, non-invasive treatments need to be considered to bone formation as low-level laser (LLL) irradiation ${ }^{4-7}$.

Low-level laser irradiation can increase bone formation through osteoblasts mitosis and higher protein deposition and consequently promoting new bone formation. LLL parameters and wavelength are important to regulate bone function. It also was showed that infrared low-level laser increases bone density and gene expression in bone formation ${ }^{7,8}$. Osteoblasts are specialized mesenchymal cells that are primarily responsible for the synthesis and deposition of the mineralized collagenrich matrix that composes bone tissue. They are effector cells for bone formation with the widely known ability to form bone tissue by secretion of alkaline phosphatase, type I collagen, proteoglycan, bone sialoprotein, and osteocalcin $(\mathrm{OC})^{8}$.

Osteocalcin has routinely been used as a serum marker of osteoblastic bone formation and believed to act in the bone matrix to regulate mineralization ${ }^{9}$. A novel function of the skeleton in the regulation of energy metabolism and fat mass has been suggested. Even if it is not possible to exclude the involvement of other bone proteins in the regulation of energy metabolism, OC seems exert not only skeletal effects but also plays a role in the regulation of angiogenesis, male reproduction and energy metabolism. A better understanding of $O C$ functions, mainly the identification of $O C$ receptors and the signaling pathway activated by OC, could also offer exciting opportunities for new therapeutic strategies in bone diseases and metabolic disturbances ${ }^{9,10}$.

The aim of this study was to evaluate protein and gene expression of osteocalcin, in vitro and in an in vivo model of ostectomy after low-level laser irradiation.

\section{Methods}

All experimental procedures were conducted under Ethical guidelines of COBEACONCEA and submitted to approval of Animal Research Ethical Committee of Universidade Federal de São Paulo (UNIFESP), protocol number 0279/2012.

\section{Animals and surgical procedure}

Twenty male Wistar rats (12 weeks, proximally $300 \mathrm{~g}$ ) were provided with regular standard rat food and water ad libitum throughout the experiment and were housed one animal per cage in a room with a 12-h light-dark cycle. Animals were assigned into two groups: A - ostectomy and laser therapy $(n=10)$ and B - ostectomy $(n=10)$. Surgery procedure was performed in all animals of both groups as described by Sella et al. ${ }^{11}$. 


\section{Low-level laser irradiation}

Group A (in vitro) received daily, after $70 \%$ of confluence, low-level laser irradiation by a Gallium-Aluminum-Arsenide laser (GaAlAs - DMC Equipment, Sao Carlos, Brazil), model Magnus Plus, $\lambda=808 \mathrm{~nm}$, power of $200 \mathrm{~mW}$, power density of $0.2 \mathrm{~W} / \mathrm{cm}^{2}$, fluency of $37 \mathrm{~J} / \mathrm{cm}^{2}$ per site, nominal dose of $2 \mathrm{~J}$, spot size of 0.02 $\mathrm{mm}^{2}$, energy per point $=1.25 \mathrm{~J}$, total energy of 1.25J and exposure time of $5 \mathrm{~s}$ per application for 13 days. Group B was submitted to the same procedure, however with the instrument in off position. Group A of in vivo received low-level laser irradiation in a single dose, one day after surgery with the same parameters and group $B$ with the laser device off. All laser parameters were described before by Sella et al. ${ }^{11}$.

\section{Euthanasia and sample collection}

After an experimental period of 13 days all animals were euthanized by an overdose of Ketamin $10 \%(3 \mathrm{~mL} / \mathrm{kg})$ and heart's blood exsanguination to perform femurs excision. Femurs were submitted to standard histological procedures (decalcification, dehydration, histological slices - $5 \mu \mathrm{m}$ ) in silanized slices to immunohistochemistry assays. Cell culture were tripsinazed by tripsin-EDTA 25\% (Sigma Chemical Co., St. Louis, MO, USA) for 10 minutes under $5 \%$ of $\mathrm{CO}_{2}$ atmosphere for cells ' liberation. Part of these cells, $10^{3}$, were fixed in formalin $10 \%$ solution and an aliquot of cells $\left(10^{3}\right)$ were kept in RNAlater (Sigma Chemical Co., St. Louis, MO, USA) to gene expression analysis and to preserve RNA sample.

In vitro experiments - cell culture

Twenty femur fragments that were excised by surgical procedure from the in vivo experimental groups composed the in vitro groups following the same division of in vivo groups ( $A$ and $B$ ). Cell culture was performed with femur fragments with proximally $5 \mathrm{~mm}$ to obtainment of osteoblasts cells according to Binderman et $a l^{12}$. The fragments were placed into PBS buffer solution ( $\mathrm{pH} \mathrm{7,4;1} \mathrm{X,} \mathrm{sterile)}$ and maintained for 15 minutes, then removed and washed in PBS buffer ( $\mathrm{pH} \mathrm{7,4;} 1 \mathrm{X}$, sterile) and maintained in DMEM culture medium (Modified Eagle Medium - Dubelcco Nutricell, Campinas, SO, Brazil) with the addition of gentamicin $(10 \mathrm{mg} / \mathrm{mL}$ - Sigma Chemical Co., St. Louis, MO, USA) and Amphotericin B $(250 \mu \mathrm{g} / \mathrm{mL}$ - Sigma Chemical Co., St. Louis, MO, USA) in sterile environment. They were subsequently submitted to mechanical and enzymatic digestion with DMEM to cell extraction, by addition of $2 \%$ of collagenase type II $(2 \mathrm{mg} / \mathrm{mL}$ - Sigma Chemical Co. St. Louis, MO, USA) for 30 minutes at $37^{\circ} \mathrm{C}$ under constant agitation. The supernatant was stored and the procedure repeated two times. The supernatants were stored and centrifuged at $3000 \mathrm{~g}$ for 10 minutes. The precipitate was resuspended in $2 \mathrm{ml}$ of DMEM containing $10 \%$ of fetal bovine serum (Invitrogen - Life Technologies, USA), gentamicin, Amphotericin $B$, ascorbic acid ( $5 \mathrm{mg} / \mathrm{mL}$ - Sigma Chemical Co. St. Louis, MO, USA), dexamethasone $(5 \mathrm{mg} / \mathrm{mL}$ - Sigma Chemical Co. St. Louis, MO, USA) and $\beta$-glycerophosphate (10 mM - Sigma Chemical Co. St. Louis, MO, USA). After this process, the quantification of cell viability was performed by vital dye trypan blue (Sigma Chemical Co., St. Louis, MO, USA) at Neubauer's chamber. The cells were seeded in plastic Petri dishes with $2 \times 10^{4}$ cells per plate supplemented with 2 $\mathrm{mL}$ of DMEM maintained at $37^{\circ} \mathrm{C}$ and $5 \% \mathrm{CO}_{2}$, the culture medium was changed every 2 days.

\section{RNA extraction, RNA quantitation and $C D N A$ Synthesis}

After 13 days total RNA was extracted from all in vitro samples with a commercial kit AxyPrep Multisource Total RNA (Axygen, Tewksbury, MA, USA) according to manufacturer instructions. For quantification 
of RNA was used $1 \mu \mathrm{L}$ of RNA and its analyzed by spectrophotometry at $260 \mathrm{~nm}$ absorbance (NanoDrop 1000 Spectrophotometer, Thermo Fisher Scientific, Wilmington, DE, USA). cDNA was synthesized from $20 \mathrm{ng}$ of total RNA, $1 \mu \mathrm{L}$ of reverse sequence of each primer, $\beta$-actin and Osteocalcin (Table 1 ) and $1 \mu \mathrm{L}$ of Superscript III (2000U/ $\mu \mathrm{L}$, Invitrogen Techonologies).

Table 1 - Primers sequences and annealing temperatures (AT) of $\beta$-actin and osteocalcin used for gene expression by real time PCR.

\begin{tabular}{ccc}
\hline Gene & Sequence & AT (ㅇ) \\
\hline$\beta$-actin & F-5'AACCGCGAGAAGATGACCCAGATCATGTTT 3' & 60 \\
R-5'AGCAGCCGTGGCCATCTCTTGCTCGAAGTC 3' & \\
Osteocalcin & F-5' AGGACCCTCTCTCTGCTCAC 3' & 60 \\
& R-5' AACGGTGGTGCCATAGATGC 3' & \\
\hline
\end{tabular}

\section{Gene expression analysis}

Gene expression was performed by real time polymerase chain reaction technique after reverse transcription (qPCR) for $\beta$-actin and Osteocalcin genes, following the primers sequences describe in Table 1 , using $2 \mu \mathrm{L}$ of CDNA and $8 \mu \mathrm{L}$ of Master Mix (Syber Green PCR Master Mix 1X; $\beta$-actin primers $0.075 \mathrm{mM}$; Osteocalcin primers $0.03 \mathrm{mM}$ and Milli-Q water to volume adjust). It was set an annealing temperature of $60^{\circ} \mathrm{C}$ and 50 cycles of denaturation, annealing and extension. All experiments were performed by ${ }^{\mathrm{T}}$ System StepOnePlus (Applied Biosystems ${ }^{\circ}$, Life Technologies Corporation) and software $A B$ Prism Step One. Gene expression was analyzed by Cycle threshold $(\mathrm{Ct})$ comparative technique $(2 \Delta \Delta \mathrm{Ct})$ after normalization between gene of interest and the housekeeping ( $\beta$-actin). The experiments were performed in triplicate.

Immunohistochemistry (in vivo) and citochemistry (in vitro)

Briefly, histological slices and fixed cells were incubated in sodium citrate buffer $0.01 \mathrm{M}$ $\mathrm{pH} 6.0$ with Tween-20 $0.05 \%$, at $100^{\circ} \mathrm{C}$ for 20 minutes for antigenic recuperation. Methanol $(0.3 \%)$ with hydrogen peroxide (10V) were used for endogenous peroxidase block. All samples were washed in PBS (1X) and incubated with primary antibody, anti-osteocalcin (1:500, Santa Cruz Technologies) overnight at 4으. Samples were washed and incubated with secondary antibody DAKO LSAB (DAKO, Glostrup, Denmark) plus System, HRP, for 20 minutes at room temperature with posterior incubation with DAB of Substrate Chromogen Solution (DAKO LSAB, Glostrup, Denmark), for five minutes at room temperature. Slices and cells were stained with metil green solution. Immunoreaction was analyzed by Image J $(\mathrm{NIH}$, free program) evaluating the color formed by the antibody reaction as describes before ${ }^{11}$.

\section{Statistical analysis}

Graph Prism $5.0^{\circ}$ was used to calculate the arithmetic mean and standard deviation. The values of $2 \Delta \Delta C t$, immunohistochemistry and cytochesmitry were statistically analyzed using Wilcoxon-Mann-Whitney test for nonparametric independent samples. It was set significance level of $5 \%(p<0.05)$.

\section{- Results}

After normalization between osteocalcin and $\beta$-actin (housekeeping) was produced $\Delta \mathrm{Ct}$ values and showed no significant differences. The expression, median 
\pm standard deviation, of groups A $4.06 \pm 3.814$ and group B $3.45 \pm 4.447$ with $p=0.756$ (Figure 1B). Immunohistochemistry (in vivo) and cytochemistry (in vitro) scores' values were, respectively, in groups $A$ (median 2.0 \pm 0.67 ) and $B(2.5 \pm 0.89)(p=1)$ (Figure $2 A, B)$ and $A$ $(1.6 \pm 1.51)$ and $B(0.3 \pm 0.82)(p=0.100)$ (Figure $1 \mathrm{~A})$ showed no statistical differences.
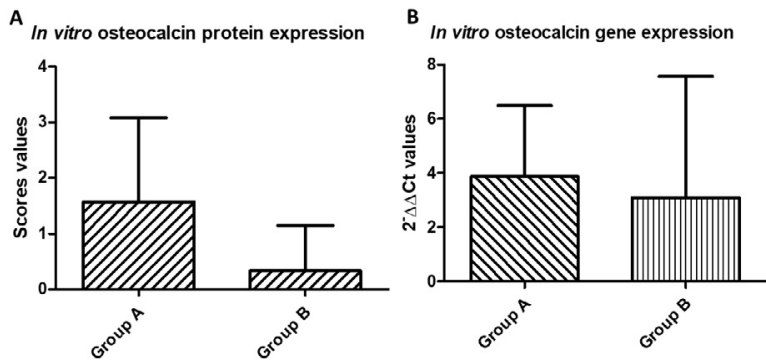

Figure 1 - Osteocalcin protein expression of in vitro groups $(\mathbf{A})$ and osteocalcin gene expression of in vitro groups (B).

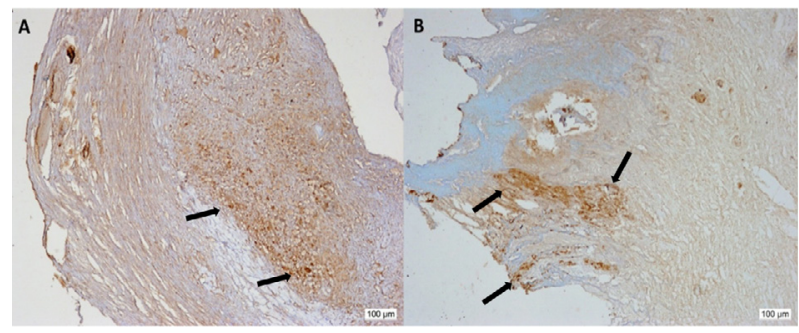

Figure2 - Immunohistochemistry section of groups A (laser) and B (no laser). Figure shows in arrows the scores obtained by reaction and presence of osteocalcin (DAB stain, $x 100)$. Osteocalcin is produced and secreted by osteoblasts to extracellular space.

\section{- Discussion}

Several studies have used osteoblastic cell cultures in the most diverse areas such as light interaction with cells, cytotoxicity, calcium flux and transport, molecular analyzes, growth factors and cell death, but most studies involve cells from young rats from 3 to 21 days and until newborns ${ }^{12-15}$. These cells have a high degree of differentiation and proliferation, especially by the high number of fibroblasts and mesenchymal cells.

In this study, unlike the literature, we worked with adult osteoblastic cells from rat femurs that naturally have a difficulty in their handling by the tissue structure itself, besides the difficulty in extracting the cells and specific phenotypic characteristic ${ }^{15}$. In addition to the cited points, adult cells are indistinguishable somatic cells, which divide only if there is a need for tissue, as well as in bone fractures, which brings our research closer to the clinical.

The choice to use adult cells is based precisely on the difficulty of this tissue and the resolution of bone fractures. The applicability of this study is related to the same difficulties that the bone tissue would find for the reestablishment of its normal activity. When observing the behavior of adult cells in vitro, it is extrapolated to the environment in which the adult and elderly patient is, since this population has greater difficulty in the process of tissue repair when compared to the pediatric patient.

Earlier studies of our group have shown the applicability of adult cells to cell culture through cytochemical, immunocytochemical and molecular evaluations. These studies aimed at aspects related to the process of bone mineralization and cellular mechanisms in the increase and/or reduction of proteins and ions involved in this process due to the use of lowlevel laser ${ }^{16,17}$.

Low-laserlaserhas photobiomodulatory properties and in previous studies evaluating the effects in vivo and in vitro, an increase in osteoblastic proliferation and growth factors and cofactors was observed for the bone mineralization process ${ }^{18}$. Light, like lowlevel laser, can be absorbed and stimulate photoreceptors acting on mitochondrial respiratory chain. These photoreceptors 
stimulate the internal and external mitochondrial membrane, altering the respective membrane potential and leading to an increase in mitochondrial metabolism and consequent increase in ATP production and oxygen consumption.

These stimulations can activate DNA, RNA and the synthesis of cell cycle regulatory proteins, increasing the speed of the mitotic cycle by intensifying the DNA synthesis, as the irradiated cells pass more quickly from the $\mathrm{G} 1$ phase to the $S$ phase of the cell cycle increasing cell division ${ }^{19}$.

The stimulation of RNA and DNA synthesis is associated with the ability of porphyrins and flavoproteins, components of the respiratory chain, to generate reactive oxygen species, such as singlet oxygen ( $\left.0^{-}\right)$. Small amounts of these species have beneficial effects by activating the mechanism of cellular mitosis, however, high doses may induce apoptosis and/or necrosis of cells irradiated with low-level laser ${ }^{20}$.

Some studies have shown the effects of LBI irradiation on osteoblasts in the gene expression of bone morphogenic protein 2 (BMP-2), osteocalcin, transforming growth factor $\beta 1(\text { TGF- } \beta 1)^{21}$, stimulation of bone proliferation and mineralization ${ }^{22}$. However, these same studies differ on LBI parameters, which may vary in wavelength, energy density and power ${ }^{23,24}$.

In our study we used the same parameters for LLL used previously by our group $^{11}$, however an unused power was chosen in clinical practice so that a larger dose of energy could be provided with a shorter application time ${ }^{25,26}$.

Corroborating our findings of osteocalcin, in a study by Wu et al. ${ }^{27}$ using LLL with $\lambda=660 \mathrm{~nm}, 4 \mathrm{~J} / \mathrm{cm}^{2}, 70 \mathrm{~mW}$ and BouvetGerbettaz et al. ${ }^{28}$ using GaAlAr LLL with $\lambda=808 \mathrm{~nm}, 4 \mathrm{~J} / \mathrm{cm}^{2}, 520 \mathrm{~mW}$ was not observed increase of osteocalcin expression, suggesting that, as the energy density is inside the therapeutic window, the laser power can be responsible to influence the gene expression process in our study, since it was used a $200 \mathrm{~mW}$ of power.

This leads to the possibility that the gene expression occurs in the initial periods of the cell culture leaving only the protein formed between the 13th and the 20th day. We must consider that the end of the expression must be associated with the presence of a mineralized bone matrix, since this is formed from the expression of the osteocalcin protein associated with calcium deposition. It is suggested that the potency used in this study had a photo inhibitory effect whereas other studies have shown an increase in osteocalcin expression either in vivo or in vitro ${ }^{29,30}$.

It should be kept in mind that in the clinic the laser is applied on the skin, while in the cell culture it is applied directly on the cells. This was why our study focused on the in vivo model that analyzed the gene and protein expression through immunohistochemical analysis of the femurs of the animals, however, no differences were observed between the irradiated and non-irradiated groups.

\section{- Conclusion}

Low-level laser irradiation with these parameters showed no up or down regulation of osteocalcin gene and protein in vivo and in vitro in the studied period and showed just a constant expression between irradiated and control. Our results suggest that low-level laser parameters influence gene and protein expression.

\section{References}

1. LeBlanc ES, Rosales AG, Black DM, Genant $H K$, Dell RM, Friess DM, Boardman DL, Bauer DC, de Papp A, Santora AC, Orwoll ES. Evaluating atypical features of femur 
fractures: how change in radiological criteria influenced incidence and demography of atypical femur fractures in a community setting. J Bone Miner Res. 2017;32(11):2304-14. doi: 10.1002/ jbmr.3221.

2. GBD 2016 DALYs and HALE Collaborators. Global, regional, and national disabilityadjusted life-years (DALYs) for 333 diseases and injuries and healthy life expectancy (HALE) for 195 countries and territories, 1990-2016: a systematic analysis for the Global Burden of Disease Study 2016. Lancet. 2017; 390(10100):1260-344. doi: 10.1016/S0140-6736(17)32130-X.

3. GBD 2015 DALYs and HALE Collaborators. Global, regional, and national disability adjusted life years (DALYs) for 315 diseases and injuries and healthy life expectancy (HALE) for 195 countries and territories, 1990-2015: a systematic analysis for the Global Burden of Diseases Injuries, and Risk Factors (GBD) 2015 Study. Lancet. 2016;388(10053):1603-58. doi: 10.1016/ S0140-6736(16)31460-X.

4. Gerber C, Mast J, Ganz R. Biological internal fixation of fractures. Arch Orthop Trauma Surg. 1990;109:295-303. PMID: 2073446.

5. Kataoka Y, Minehara H, Kashimi F, Hanajima T, Yamaya T, Nishimaki H, Asari Y. Treatment combining emergency surgery and intraoperative interventional radiology for severe trauma. Injury. 2016;47(1):59-63. doi: 10.1016/j.injury.2015.09.022.

6. Rompe JD, Eysel D, Hopf C, Vogel J, Küllmer $\mathrm{K}$. Extracoropeal shockwave treatment of delayed bone healing: a critical assessment. Unfallchirurg. 1997;100:845-9. PMID: 9446241.

7. Abd-Elaal AZ, El-Mekawii HA, Saafan AM, El Gawad LA, El-Hawary YM, Abdelrazik MA. Evaluation of the effect of low-level diode laser therapy applied during the bone consolidation period following mandibular distraction osteogenesis in the human. Int. J. Oral Maxillofac Surg. 2015;44(8):989-97. doi: 10.1016/j.ijom.2015.04.010.

8. Favaro-Pipi E, Ribeiro DA, Ribeiro JU, Bossini P, Oliveira P, Parizotto NA, Tim C, de Araujo HS, Renno AC. Low-level laser therapy induces differential expression of osteogenic genes during bone repair in rats. Photomed Laser Surg. 2011;29(5):311-7. doi: $10.1089 /$ pho.2010.2841.

9. Zoch ML, Abou DS, Clemens TL, Thorek DLJ, Riddle RC. In vivo radiometric analysis of glucose uptake and distribution in mouse bone. Bone Res. 2016;4:16004. doi: 10.1038/boneres.2016.4.

10.Neve A, Corrado A, Cantatore FP. Osteocalcin: skeletal and extra-skeletal effects. J Cell Physiol. 2013;228(6):1149-53. doi: $10.1002 /$ jcp.24278.

11.Sella VRG, Bomfim FRC, Machado PCD, Morsoleto MJMS, Chohfi M, Plapler, H. Effect of low-level laser therapy on bone repair: a randomized controlled experimental study. Lasers Med Sci. 2015;30(3):1061-8. doi: 10.1007/s10103-015-1710-0.

12.Binderman I, Duksin D, Harell A, Katzir $E$, Sachs L. Formation of bone tissue in culture from isolated bone cells. J Cell Biol. 1974;61:427-39. PMID: 4597345.

13. Meszaros JG, Karin NJ. Osteoblasts express the PMCA1b isoform of the plasma membrane Ca2+-ATPase. J Bone Miner Res. 1993;8(10):1235-40. doi: 10.1002/ jbmr.5650081011.

14.Ueda $Y$, Shimizu N. Effects of pulse frequency of low-level laser therapy (LLLT) on bone nodule formation in rat calvarial cells. J Clin Laser Med Surg. 2003;21(5):2717. doi: $10.1089 / 104454703322564479$.

15.Spadaro JA, Bergstron WH. In vivo and in vitro Effects of pulsed electromagnetic field on net calcium flux in rat calvarial bone. Calcif Tissue Int. 2002;70(6):496-502. doi: 10.1007/s00223-001-1001-6.

16.Gilbert L, He X, Farmer P, Rubin J, Drissi H, Van Wijnen AJ, Lian JB, Stein GS, Nanes MS. Expression of the osteoblast differentiation factor RUNX2 (Cbfa1/AML3/Pebp2_A) is inhibited by tumor necrosis factor-alpha. J Biol Chem. 2002;277(4):2695-701. doi: 10.1074/jbc.M106339200.

17.Freshney RI. Culture of animal cells: a manual of basic technique. Wiley Blackwell; 2010. doi: 10.1002/9780470649367.

18.Bomfim FRC, Sella VRG, Zanaga JQ, Simionatto N, Nouailhetas VLA, Plapler $H$. RT-PCR standardization and bone mineralization after low-level laser therapy on adult osteoblast cells. Proc. SPIE 8926, Photonic Therapeutics and Diagnostics X. 2014;(1)89263S. doi: 10.1117/12.2037340. 19.Karu TI. Effects of visible radiation on 
cultured cells. Photochem Photobiol. 1990;52(6):1089-98. PMID: 2087499.

20.Kreisler $M$, Christoffers $A B$, Willershausen B, d'Hoedt B. Low-level 809nm GaAlAs laser irradiation increases the proliferation rate of human laryngeal carcinoma cells in vitro. Lasers Med Sci. 2003;18(2):100-3. doi: 10.1007/s10103-003-0265-7.

21. Renno ACM, McDonnell PA, Parizotto NA, Laakso EL. The effects of laser irradiation on osteoblast and osteosarcoma cell proliferation and differentiation in vitro. Photomed Laser Surg. 2007;25(4):275-80. doi: 10.1089/pho.2007.2055.

22. Pyo SJ, Song WW, Kim IR, Park BS, Kim $\mathrm{CH}$, Shin SH, Chung IK, Kim YD. Low-level laser therapy induces the expressions of BMP-2, osteocalcin, and TGF- $\beta 1$ in hypoxiccultured human osteoblasts. Lasers Med Sci. 2013;28(2):543-50. doi: 10.1007/ s10103-012-1109-0.

23.Kiyosaki T, Mitsui N, Suzuki N, Shimizu $\mathrm{N}$. Low-level laser therapy stimulates mineralization via increased Runx2 expression and ERK phosphorylation in osteoblasts. Photomed Laser Surg. 2010;28(Suppl 1):S167-72. doi: 10.1089/ pho.2009.2693.

24.Coombe AR, Ho C-TG, Darendeliler MA, Hunter N, Philips JR, Chapple CC, Yum LWP. The effects of low laser irradiation on osteoblastic. Cells Clin Orthod Res. 2001;4:3-14. PMID: 1553080.

25. Freitas IGF, Baranauskas V, Cruz-HÖfling MA. Laser effects on osteogenesis. Appl
Surface Sci. 2000;154-155:548-54. doi: 10.1016/S0169-4332(99)00431-6.

26.Merli LAS, Dos Santos MTBR, Genovese WJ, Faloppa F. Effect of low-intensity laser irradiation on the process of bone repair. Photomed Laser Surg. 2005;23(2):212-5. doi: 10.1089/pho.2005.23.212.

27.Wu JY, Chen CH, Yeh LY, Yeh ML, Ting CC, Wang $\mathrm{YH}$. Low-power laser irradiation promotes the proliferation and osteogenic differentiation of human periodontal ligament cells via cyclic adenosine monophosphate. Int J Oral Sci. 2013;5(2):8591. doi: 10.1038/ijos.2013.38.

28. Bouvet-Gerbettaz S, Merigo E, Rocca JP, Carle GF, Rochet N. Effects of lowlevel laser therapy on proliferation and differentiation of murine bone marrow cells into osteoblasts and osteoclasts. Lasers Surg Med. 2009;41(4):291-7. doi: 10.1002/ Ism.20759.

29.Walter C, Pabst AM, Ziebart T. Effects of a low-level diode laser on oral keratinocytes, oral fibroblasts, endothelial cells and osteoblasts incubated with bisphosphonates: an in vitro study. Biomed Rep. 2015;3(1):14-8. doi: 10.3892/ br.2014.389.

30.Pagin MT, Oliveira FA, Oliveira RC, Sant'Ana $A C P$, Rezende MLR, Greghi SLA, Damante CA. Laser and light-emitting diode effects on pre-osteoblast growth and differentiation. Lasers Med Sci. 2014;29(1):55-9. doi: 10.1007/s10103-012-1238-5.

\section{Correspondence:}

Hélio Plapler

Disciplina de Técnica Operatória e Cirurgia Experimental, UNIFESP

Rua Botucatu, 740

04023-062 São Paulo - SP Brasil

helio@plapler.com.br

Received: May 10, 2018

Review: July 12, 2018

Accepted: Aug 10, 2018
Conflict of interest: none

Financial sources: FAPESP, CAPES and CNPq

${ }^{1}$ Research performed at Operative Technique and Experimental Surgery Division, Department of Surgery, Universidade Federal de São Paulo (UNIFESP), and Laboratory of Molecular Biology of FHO-UNIARARAS, Brazil. Part of PhD degree thesis, Postgraduate Program in Interdisciplinary Surgical Science. Tutor: Prof. Dr. Hélio Plapler. 